\title{
Failure Analysis of Deep Composite Roof Roadway and Support Optimization of Anchor Cable Parameters
}

\author{
Chen Li $\mathbb{D}^{1},{ }^{1}$ Wenlong Zhang $\mathbb{D}^{1},{ }^{1}$ Tianhong Huo, ${ }^{1}$ Rui Yu, ${ }^{2}$ Xidong Zhao $\mathbb{D},{ }^{3}$ and Ming Luo ${ }^{1}$ \\ ${ }^{1}$ School of Energy \& Mining Engineering, China University of Mining and Technology (Beijing), Beijing 100083, China \\ ${ }^{2}$ Wang Jialing Coal Mine, China Coal Energy Research Institute Co., Ltd., Yuncheng 043301, China \\ ${ }^{3}$ School of Safety Engineering, North China Institute of Science \& Technology, Langfang 065201, China
}

Correspondence should be addressed to Chen Li; 13120008810@163.com and Xidong Zhao; xdz523@126.com

Received 9 May 2021; Accepted 1 July 2021; Published 16 July 2021

Academic Editor: Haiyan Wang

Copyright (c) 2021 Chen Li et al. This is an open access article distributed under the Creative Commons Attribution License, which permits unrestricted use, distribution, and reproduction in any medium, provided the original work is properly cited.

The stability of the roadway surrounding rock is the key factor of underground mining. Roof subsidence occurred during roadway excavation in the Menkeqing Coal Mine. For the sake of safety, it was decided to stop tunneling project and strengthen roadway support, which resulted in a delay of the construction period and economic damage. To maintain the stability of the surrounding rock, we carried out a systematic study through field monitoring, theoretical analysis, and numerical simulation. The deformation and failure law of the surrounding rock, roof structure characteristics, and mechanical properties of the surrounding rock were obtained by field monitoring. The failure characteristics and forms of deep composite roof roadway are further analyzed. The key points of stability of the roadway surrounding rock of soft rock composite laminated roof are obtained by theoretical analysis, i.e., improving the effective stress diffusion efficiency of the anchor cable through the reasonable arrangement of the anchor cable. We use FLAC numerical simulation software to study the influence of different supporting parameters of anchor cable on the stress diffusion in the surrounding rock and put forward the optimal parameters. The optimized support parameters have been applied in the field, and the ideal results have been obtained.

\section{Introduction}

At present, the mining of coal resources in China is gradually developing to deep mining $[1,2]$. Compared with shallow coal mining, deep coal mining is affected by higher stress and a more complex geological structure. The coal measure strata are mostly formed by sedimentation, and the roof of coal seam is mostly a layered structure [3]. Therefore, the deep mining roadway often shows stronger deformation failure and higher repair frequency than the shallow mining roadway $[4,5]$.

The high deviated stress field around the roadway during mining can be artificially intervened by adjusting the mining layout [6-9]. However, the high-stress field of the first mining face in the tunneling stage cannot be changed, even if the strong support on the regional stress field of the roadway is very little change [10]. In the face of high-stress mining roadway deformation and failure, it is necessary to clearly understand the rock structure and rock strength parameters
[11-13]. These data are the basis for analyzing the deformation and failure mechanism of the surrounding rock and also the basis for putting forward the corresponding control measures of the surrounding rock [14-16]. At present, the surrounding rock stability control of mining roadway mainly depends on the active support of rebar bolt and anchor cable $[17,18]$. Because the rebar bolt length is short and the support resistance is small, there are some hidden dangers in the support effect when the damage range of the surrounding rock is larger than the length of the rebar bolt. Anchor cable support resistance is large, but the overall elongation is small and the use cost is high. Besides, the high density of the anchor cable is easy to cause the hanging roof of goaf [19]. Therefore, the reasonable arrangement of the anchor cable is of great significance to the stability control of the surrounding rock $[20,21]$.

We have carried out detailed mine pressure monitoring and geological investigation on the project site. On this basis, combined with numerical simulation analysis, the instability 
mechanism of the composite roof is obtained. In addition, we further study the mechanism of anchor cable and stress diffusion effect of different anchor cable arrangements in the roof. According to the research results, the anchor cable support scheme is optimized, and the research results have a guiding significance for other mining roadway engineering in this mine.

\section{Project Profile}

2.1. Engineering Geology and Support Conditions. The Menkeqing Coal Mine is located in the Hujert Mining Area, Wushen Banner, Ordos City, Inner Mongolia Autonomous Region. Menkeqing Coal Mine is a typical deep mining mine. The average buried depth of 2-2 coal seam is $760 \mathrm{~m}$, and the average coal thickness is $2.63 \mathrm{~m}$. The designed length of the 2201 return air roadway is $1760 \mathrm{~m}$, and the designed section width $\times$ height of the roadway is $5.4 \mathrm{~m} \times 2.5 \mathrm{~m}$, which is driven along the floor of the coal seam. The geological exploration borehole of 2-2 coal seam shows that the roof structure is complex, the immediate roof is composed of medium sandstone, sandy mudstone, fine sandstone, and argillaceous interlayer, and the surrounding rock of the roof is rich in water.

The initial support of the roadway is a combined support design of rebar bolt-anchor net-anchor cable. The coal pillar rib and roof are $\Phi 20 \times 2300 \mathrm{~mm}$ rebar bolt support, and the working face rib is $27 \times 2300 \mathrm{~mm}$ FRP bolt support. Row spacing between bolts is $800 \times 800 \mathrm{~mm}$. The roof anchor net is made of steel belt made of $\Phi 12 \mathrm{~mm}$ round steel, with a length of $5400 \mathrm{~mm}$. Roof anchor cable specification is $\Phi$ $21.8 \times 8300 \mathrm{~mm}$ and row spacing $2400 \times 2400 \mathrm{~mm}$, as shown in Figure 1.

2.2. Failure Law of the Surrounding Rock. Water drenching phenomenon appeared in 2201 return air roadway from $800 \mathrm{~m}$. The roof sag tendency was obvious after roadway excavation and even the roof leakage occurred locally. Therefore, to avoid the continuous roof sag, reinforcement support was carried out in the corresponding area, i.e., two rows of anchor cable were supported again in the middle of the two rows of anchor cables and two anchor cables for each row, and combined reinforcement support was carried out with single hydraulic pillar and I-steel. In addition, $\varphi 200 \mathrm{~mm}$ pine wooden point post support was set as a warning, as shown in Figure 2. To be on the safe side, roadway excavation was suspended. According to the LBY-2 roof separation instrument installed on the roof during tunneling, the deformation and failure of the surrounding rock within the range of $0 \sim 5 \mathrm{~m}$ of the roof can be obtained, as shown in Figure 3.

In the range of $800 \mathrm{~m} \sim 1200 \mathrm{~m}$, the roof sag of the roadway reached $80 \sim 130 \mathrm{~mm}$ only under the influence of tunneling. Bedding failure exists in the shallow surrounding rock of $0 \sim 2.5 \mathrm{~m}$ and the deep surrounding rock at $2.5 \sim 5 \mathrm{~m}$ of the roof. The average beding separation of the surrounding rock in the shallow part of this section is $59.3 \mathrm{~mm}$, while the average beding separation of the surrounding rock in the deep part is $48.2 \mathrm{~mm}$. Although the shallow deformation accounted for $55.16 \%$, it did not take an absolute advantage.

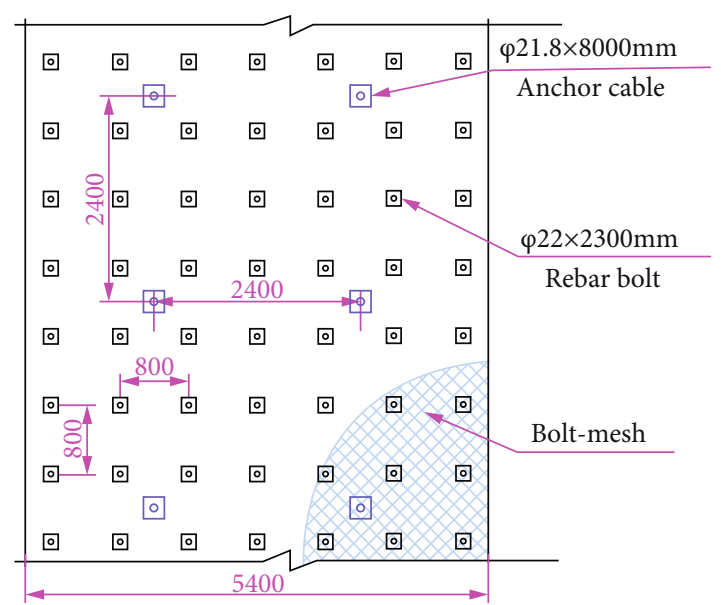

FIGURE 1: The roof support plan of 2201 return air roadway.

Therefore, from the perspective of quantitative analysis, there were potential unstable strata within $5 \mathrm{~m}$ of the roadway roof. In general, the beding separation amount in the shallow part of the roof is larger, as shown in Figure 3(a). Figure 3(b) shows the bed separation curve at $1050 \mathrm{~m}$. It can be seen from the figure that the roof surrounding rock was not completely stable within 15 days after roadway excavation, and the deep roof was basically stable after reinforcement on the 16th day, but the shallow surrounding rock was still stable after 4 days. Therefore, it is still necessary to optimize the original supporting parameters according to the geological conditions.

\section{Instability Analysis of Composite Roof}

3.1. Roof Structure Detection of Roadway. To clarify the relationship between roof subsidence and rock distribution and understand the development characteristics of roof fractures, a ZXZ20-Z roof borehole detector was used to detect the roof structure at $800-1200 \mathrm{~m}$ of 2201 return air roadway. The average spacing of detection points was $65 \mathrm{~m}$, and the detection results of the roadway roof rock distribution were shown in Figure 4.

As can be seen from Figure 4, the roof of 2201 return air roadway has the feature of composite lamination, and there are 6 kinds of rock strata distributed within $8 \mathrm{~m}$ from bottom to top of the immediate roof. Especially within the range of $5 \mathrm{~m}$ above the roof, the average thickness of the rock layer is only $1 \mathrm{~m}$. The siltstone layer contains an interlayer of mudstone with an average thickness of $0.38 \mathrm{~m}$. Local coal lines are developed in the roof. Peep detection shows that there is still a broken zone in the sandy mudstone layer, and the maximum damage range of the surrounding rock in the deep roof is up to $4.8 \mathrm{~m}$. The borehole in the mudstone interlayer has an obvious bed separation zone. In contrast, the destruction of th shallow surrounding rock is more obvious. The separation, fragmentation, and cavitation are the most serious in the middle sand strata.

The vertical stress of the original rock in 2201 air return roadway is about $19 \mathrm{MPa}$. According to the mining coefficient of 3 , the mining stress of the roadway will be about $57 \mathrm{MPa}$ in the later period. Therefore, the reduction of 


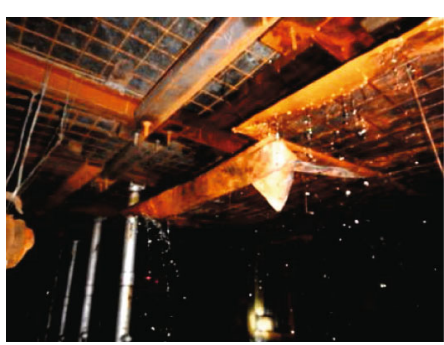

(a) Hydraulic single prop support

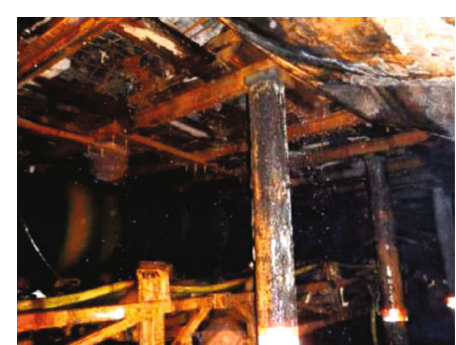

(b) Wooden point post support

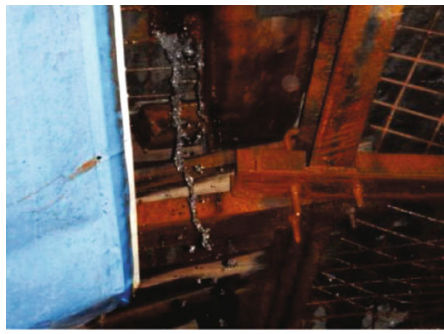

(c) Borehole water

FIgURE 2: Damage of tunneling roadway (roof water spray).

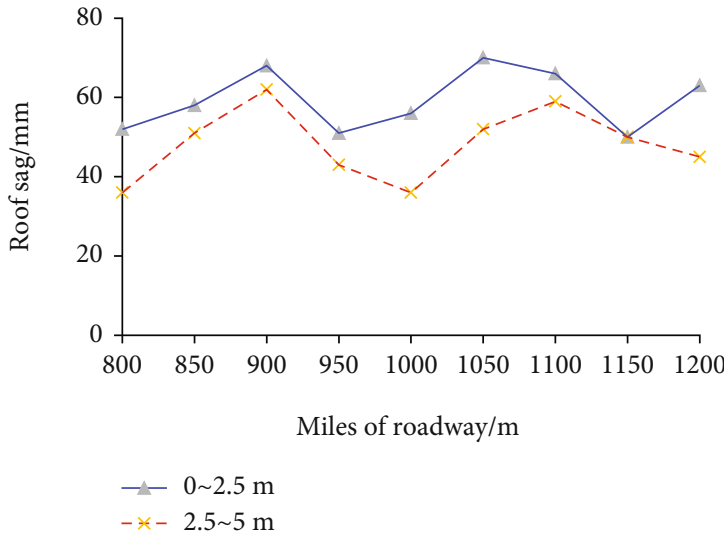

(a) Strata separation law in the $800 \mathrm{~m} \sim 1200 \mathrm{~m}$ section

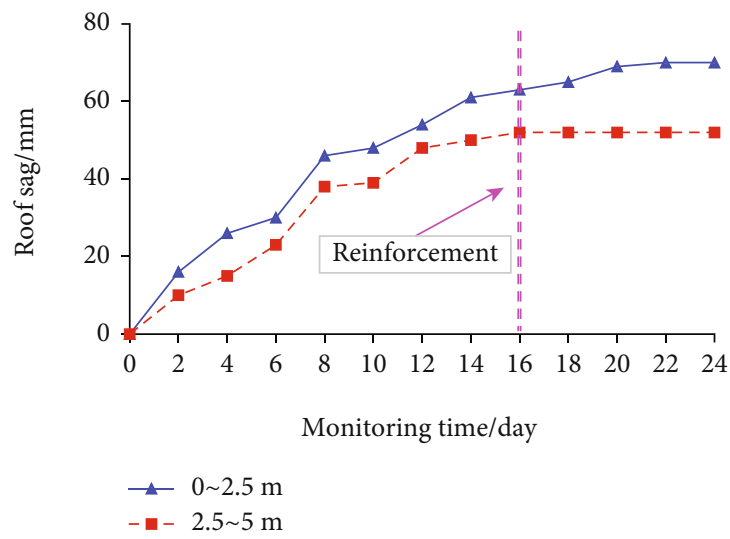

(b) Strata separation rule at $1050 \mathrm{~m}$

Figure 3: Separation curve in roof sag section.

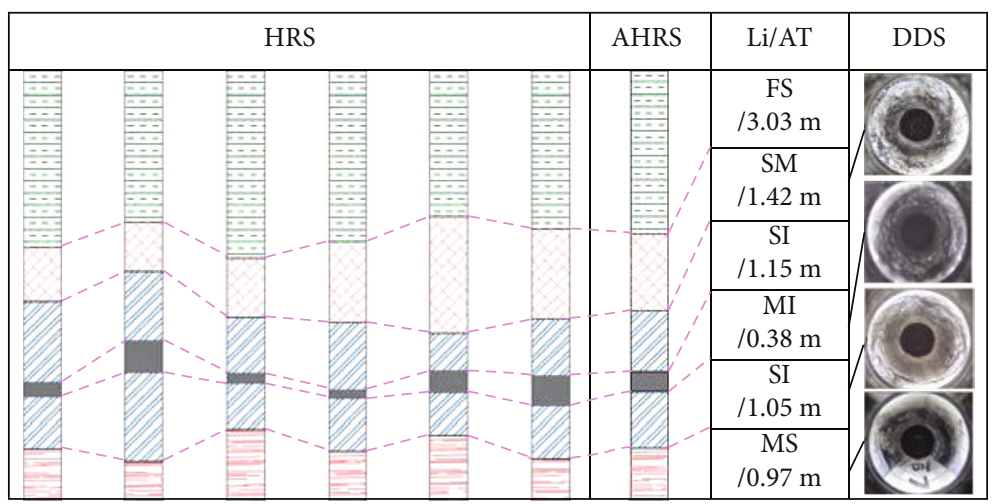

FIGURE 4: Roof structure survey results (where HRS: histogram of roof strata; AHRS: average histogram of roof strata; Li: blithology; AT: average tickness; DDS: drilling detection screenshot; FS: fine sandstone; SM: sandy mudstone; SI: siltstone; MI: mudstone interlayer; MS: medium sandstone). 


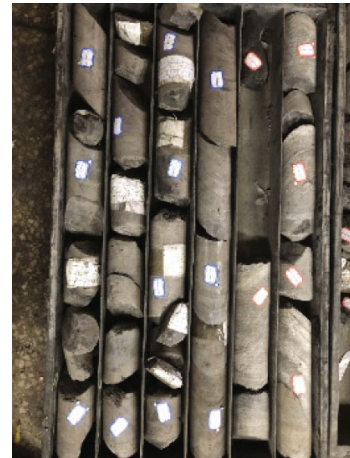

(a) Rock core

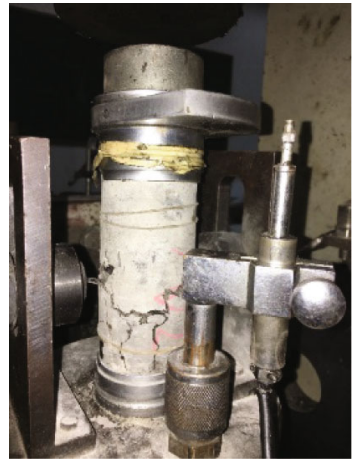

(c) Compression test

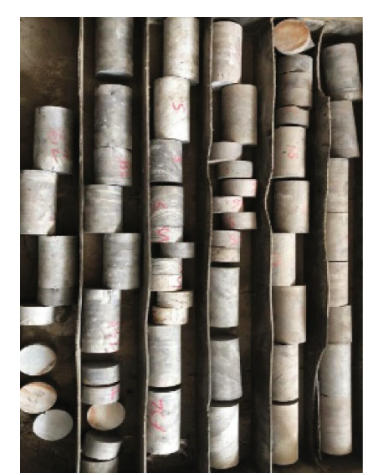

(b) Test specimen

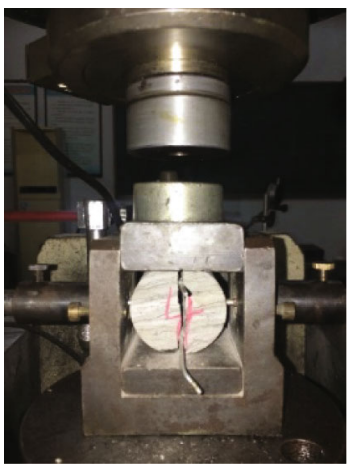

(d) Tensile test

FIGURE 5: Mechanical test process of the surrounding rock.

TABLE 1: Rock mechanic test results.

\begin{tabular}{|c|c|c|c|c|c|c|c|c|}
\hline \multirow{2}{*}{$\mathrm{Li}$} & \multicolumn{4}{|c|}{ Normal conditions } & \multicolumn{4}{|c|}{ Immersion conditions } \\
\hline & $\sigma_{c} / \mathrm{MPa}$ & $\sigma_{t} / \mathrm{MPa}$ & $\mathrm{C} / \mathrm{MPa}$ & $f 1^{\circ}$ & $\sigma_{c} / \mathrm{MPa}$ & $\sigma_{t} / \mathrm{MPa}$ & $\mathrm{C} / \mathrm{MPa}$ & $f 1^{\circ}$ \\
\hline GR & 40 & 3.8 & 5.6 & 35 & 34 & 3.1 & 4.6 & 32 \\
\hline MS & 35 & 2.2 & 4.5 & 36 & 26 & 1.7 & 3.2 & 35 \\
\hline FS & 38 & 2.8 & 5.9 & 31 & 28 & 1.5 & 1.9 & 30 \\
\hline SM & 15 & 1.3 & 2.2 & 28 & 8 & 0.8 & 0.7 & 26 \\
\hline SI & 32 & 3.5 & 4.4 & 35 & 23 & 2.5 & 2.1 & 32 \\
\hline MU & 18 & 2.3 & 2.5 & 30 & 5 & 0.7 & 0.6 & 25 \\
\hline SI & 33 & 3.4 & 4.5 & 36 & 24 & 2.5 & 1.8 & 35 \\
\hline MS & 30 & 2.8 & 3.4 & 33 & 19 & 1.7 & 2.2 & 30 \\
\hline
\end{tabular}

Where GR: grit; MU: mudstone; $\sigma_{c}$ : compressive strength; $\sigma_{t}$ : tensile strength; C: cohesion; f: internal friction angle.

tangential stress under the action of strong mining stress will lead to serious damage to the roadway with small layer thickness, weak interlayer, and water-rich roof [22]. There is a hidden danger of roof caving.

3.2. Mechanical Parameter Test of the Surrounding Rock. To understand the mechanical difference between the normal condition of the roof surrounding rock and the water pouring condition, the core was drilled in the backing chamber at $650 \mathrm{~m}$ of 2201 return air roadway. The diameter of the core drilling hole is $\Phi 8 \mathrm{~mm}$, the length of the core is $15 \mathrm{~m}$, and the inclination is $80^{\circ}$. After the core is encapsulated, the rock mechanic test is carried out in the laboratory. The test pro- cess is shown in Figure 5, and the rock mechanic test results are shown in Table 1.

When the immediate roof of 2201 air return roadway is in water content condition, the rock strength is affected, among which the sandstone mudstone and mudstone have stronger softening properties. The buried depth of 2201 return air roadway is $670 \mathrm{~m}$, and the vertical stress of the original rock of coal seam is about $19 \mathrm{MPa}[3,12,22]$. Therefore, under the same stress action, the strength of the surrounding rock in the water-pouring area of the roof is weakened, and it is easier to produce a large range of plastic zone. At the same time, the plastic zone of the surrounding rock is accompanied by the strong expansion pressure acting 


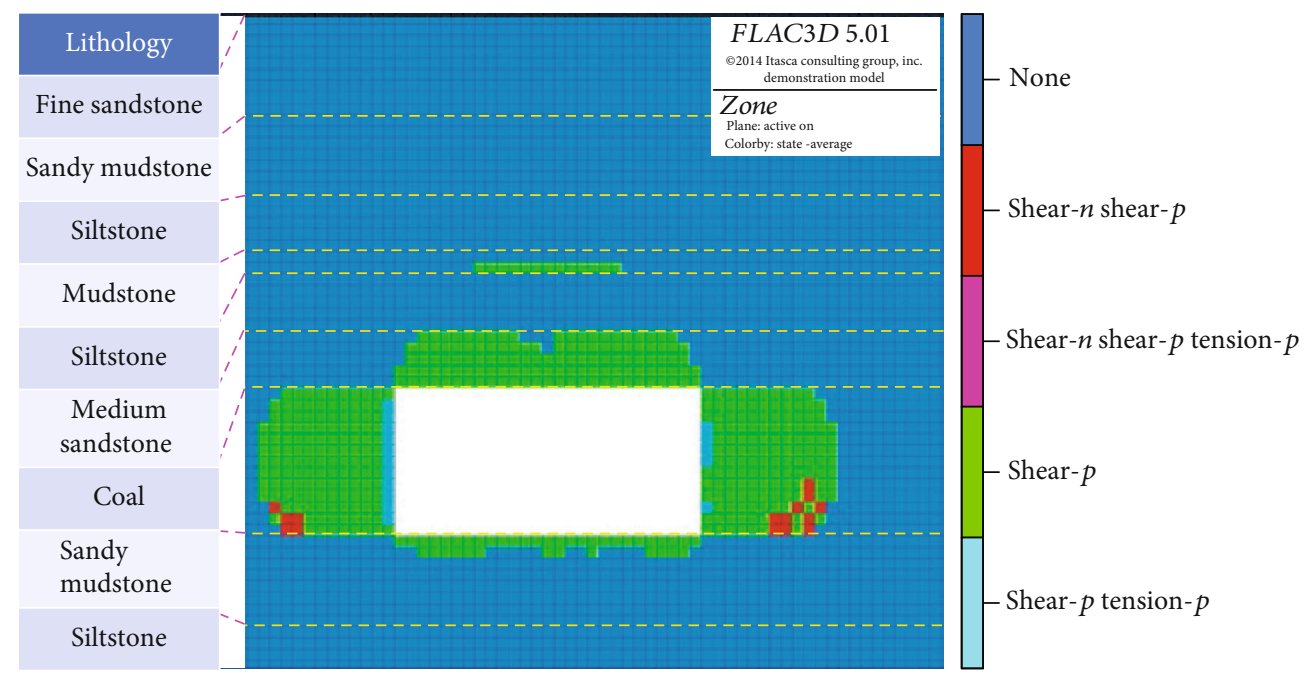

(a) Normal conditions

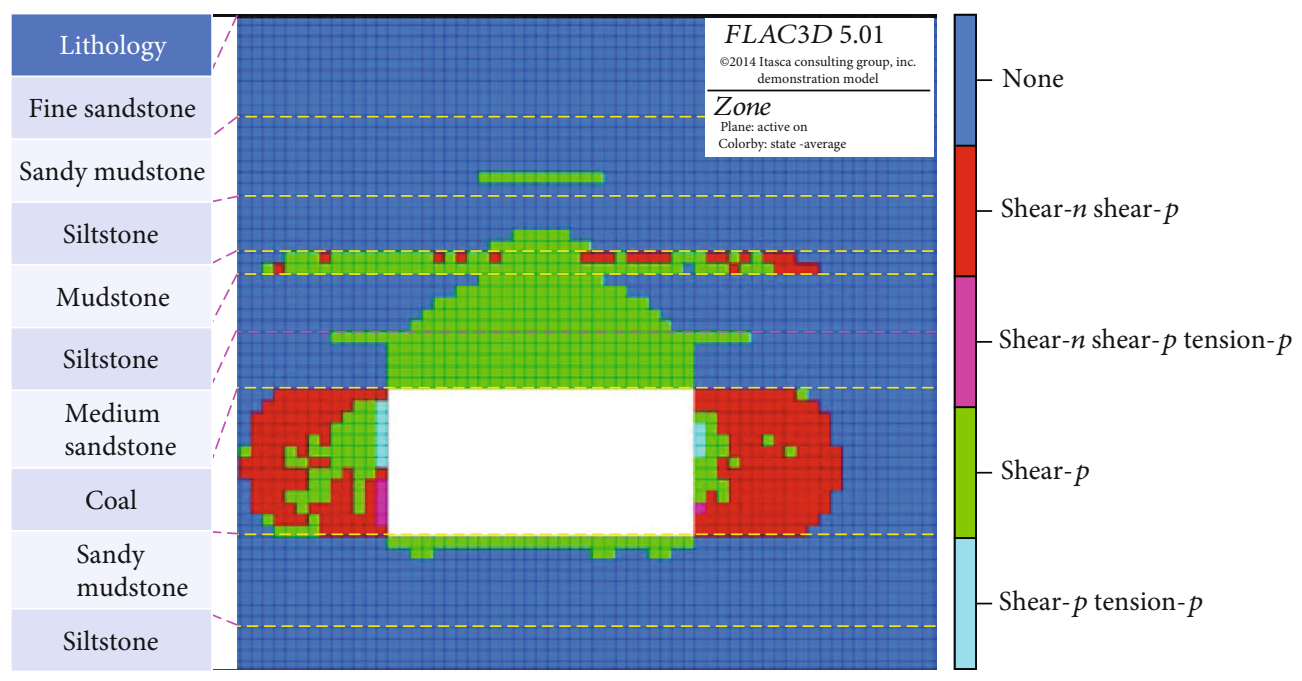

(b) Surrounding rock softening

FIGURE 6: Distribution of plastic zone in the roadway surrounding rock.

on the roof, which intensifies the potential instability probability of the roof [23]. In addition, the degree of softening of different rock strata by water is not consistent, which leads to the great strength difference between rock strata. The poor cohesion between layers further aggravates the instability of the roof separation layer.

3.3. Failure Characteristic of the Surrounding Rock. Through the detection of the roof structure of the roadway, it is found that the roof has obvious rock formation and contains mudstone interlayer with an average thickness of $0.4 \mathrm{~m}$. The mechanical properties of different rock strata in the roof were obtained by borehole core test of surrounding rock mechanics. The mechanical properties of the surrounding rock decrease sharply after water softening. Based on this, a $50 \mathrm{~m} \times 50 \mathrm{~m}$ FLAC numerical model was established to analyze the influence of interlayer and lithology on the failure of the roadway surrounding rock [24-26]. The rock strata were fine tuned to facilitate mesh division, and the mesh size was $0.2 \mathrm{~m} \times 0.2 \mathrm{~m}$. The lateral and bottom boundary of the model was fixed, and the upper boundary was compensated with $19 \mathrm{MPa}$ normal stress. The gravity stress gradient and pressure coefficient in the model were 0.025 and 1.2, respectively. The Mohr-Coulomb constitutive model was adopted in the simulation.

The numerical model results are shown in Figure 6. Figure 6(a) shows the plastic zone distribution of the surrounding rock under normal conditions. At this time, due to the weak strength of the coal seam rock, the plastic zone of the surrounding rock at the roadway ribs under strong vertical stress is $2.4 \mathrm{~m}$. The damage range of the immediate roof of the roadway is $1 \mathrm{~m}$, and the whole medium sand strata are reduced to a plastic zone. There is no plastic failure zone in siltstone due to its high rock strength, but there is a small plastic zone with a thickness of $0.2 \mathrm{~m}$ in the mudstone interlayer with weaker lithology. Figure 6(b) shows the distribution of plastic zone in surrounding rock of roadway when the surrounding rock is softened. Compared with 
Figure 6(a), the softening of rock strength leads to a sharp expansion plastic zone and the failure depth above the roof. In particular, the extension of the mudstone interlayer is particularly obvious.

The change of the position and thickness of interlayer and the change of the strength of the surrounding rock seriously affect the morphology and size of the plastic zone of the surrounding rock. Under normal circumstances, rebar bolt support of roof can maintain the stability of roadway. However, under the condition of water softening of the surrounding rock, the anchorage part of the rebar bolt is located in the plastic zone. It is easy to cause the overall sag of the surrounding rock within the range of rebar bolt. In this case, the function of rebar bolt is limited, and the stability of surrounding rock is mainly maintained by anchor cable. The anchor cable not only needs to suspend the potentially unstable rock strata in the roof stable rock strata but also should have a reasonable arrangement so that the support resistance can fully diffuse in the surrounding rock.

3.4. Analysis of Failure Mode of Composite Roof. The direct roof of 2201 return air roadway is a composite roof with small rock thickness, poor interlayer cohesiveness, and local coal line development. Usually under such roof conditions, if the roadway is excavated, there will be obvious layer separation, and it is difficult to form a self-supporting structure, resulting in roof safety accidents [27].

The failure forms of the composite roof can be summarized into three types, such as flexural failure, integral separation, and weak plane slip [28], as shown in Figure 7. The roof flexural failure is shown in Figure 7(a). At this time, the rebar bolt should pass through multiple separation positions as far as possible, and the rebar bolt should be anchored into the deep of the stable rock strata. In this case, the roof of 2201 return air roadway has the disadvantages of insufficient rebar bolt density and sufficient length due to complex strata stratification within $5 \mathrm{~m}$. The overall roof separation damage is shown in Figure 7(b). At this time, the anchor cable support density should be increased, and the preload should be increased. In this case, the roof support of 2201 return air roadway has the shortcoming of insufficient anchor cable support strength. The situation of the roof with a weak surface is shown in Figure 7(c). At this time, rebar bolt and anchor cable combined support with grouting modification to give full play to the self-supporting capacity of the surrounding rock which is one of the best support methods. The roof of 2201 return air roadway only contains weak interlayers with few weak surfaces. Grouting has not been considered for the time being.

\section{Optimization of Strong Supporting Parameters of the Anchor Cable}

4.1. Analysis of Supporting Action of the Anchor Cable. In deep mining, the change of anchor cable supporting parameters has a limited effect on the plastic zone of the surrounding rock when the mechanical properties of surrounding rock and the stress environment are given. However, changing the supporting parameters of anchor cable plays an important role in the stability control of the surrounding rock in the plastic zone $[29,30]$. The rebar bolt of layered composite roof roadway is mainly aimed at the shallow surrounding rock and combined with the shallow rock to form the "anchor beam" structure. The anchor cable with stronger support strength can suspend the shallow "anchor beam" structure in the deep stable rock strata. In addition, the strong anchor cable can effectively control the slip of weak surface and restrain the formation of new cracks. The high prestress of anchor cable can increase the friction and shear strength between rock layers by increasing the normal restraint of composite layered rock masses. The length of the anchor cable makes the high prestress of the anchor cable effectively diffuses in the deep strata and improves the integrity of the surrounding rock [31].

The reinforcement of the composite roof surrounding rock by anchor cable support is mainly through the joint action of anchor cable monomer, anchoring agent, and tray. According to the elastic mechanic's theory, the mechanical model of interaction between rock strata and anchor cable of the composite roof is established, as shown in Figure 8.

Assuming that the anchor cable and the rock mass within the influence range meet axisymmetry [31], the axial balance equation of the anchor cable element body is shown in Eq. (1).

$$
\frac{\partial \sigma_{z z}}{\partial_{z}}+\frac{1}{r}\left[\frac{\partial\left(r \tau_{r z}\right)}{\partial_{r}}\right]=0,
$$

where $\sigma_{z z}$ is the axial stress of anchor cable infinitesimal body; $\tau_{r z}$ is the shear stress of anchor cable infinitesimal body.

For anchor cable, the following relationship exists:

$$
\frac{\mathrm{d} \sigma_{z z}^{\mathrm{f}}(z)}{\mathrm{d}_{z}}+\frac{2}{a} \tau(z)=0
$$

where $\sigma_{z z}^{\mathrm{f}}(z)$ is the average axial stress of the anchor cable; $a$ is the radius of anchor cable.

The constitutive equation of rock mass is

$$
\tau(r, z)=G_{m} \gamma=G_{m} \frac{\mathrm{d}_{w}}{\mathrm{~d}_{r}},
$$

where $G_{m}$ is the shear modulus of deep surrounding rock mass; $w$ is the axial displacement of the deep surrounding rock mass.

The equilibrium condition of anchor cable and the crosssection force affecting the microsegment of rock mass is

$$
\overline{\sigma_{m}}=-\frac{a^{2}}{b^{2}-a^{2}} \sigma^{\mathrm{f}} .
$$




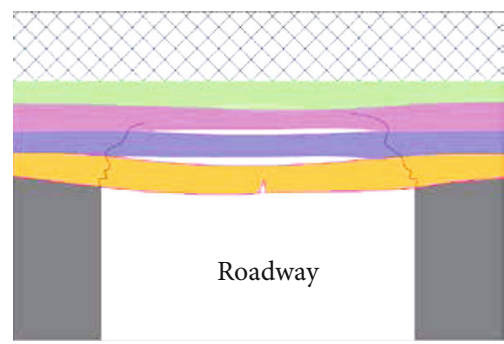

(a) Flexural failure

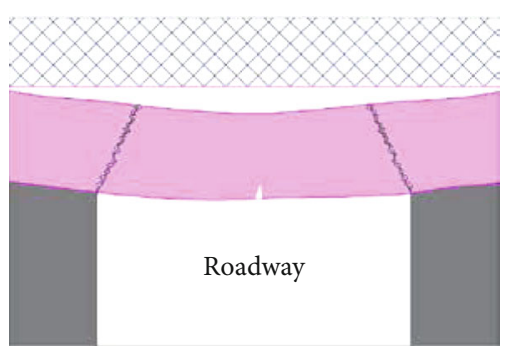

(b) Integral separation

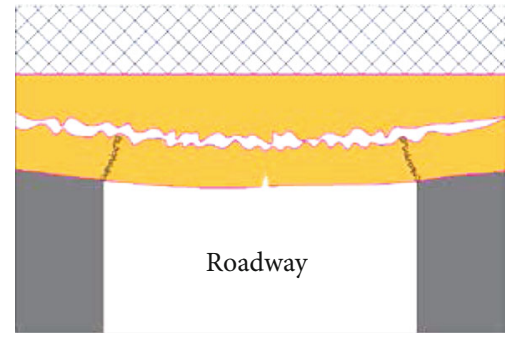

(c) Weak plane slip

FIGURE 7: Composite roof failure mode.

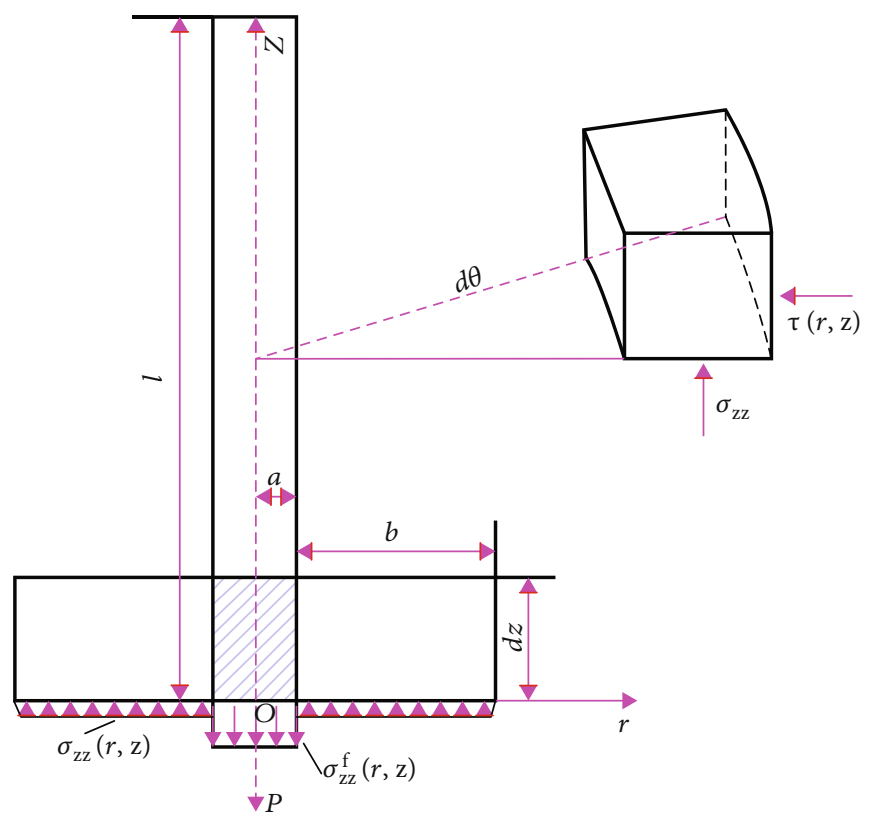

FIGURE 8: The model anchor cable and its influence on rock mass.

The boundary conditions are

$$
\left\{\begin{array}{l}
\mathrm{z}=0, \sigma^{\mathrm{f}}(z)=\frac{P}{\pi a^{2}}, \\
z=l, \sigma^{\mathrm{f}}(l)=0,
\end{array}\right.
$$

where $P$ is the pretension; $l$ is the length of anchor cable.

By analyzing the axial stress balance equation of the anchor cable element body through Eq. (1)-(5), the axial stress of the anchor cable and the shear stress of the interface between the anchor cable and the surrounding rock mass can be obtained, as shown in Eqs. (6) and (7).

Axial stress of anchor cable is as follows:

$$
\sigma(\mathrm{z})=\frac{P}{\pi \mathrm{a}^{2}}[\cosh (k z)-c \tanh (k l) \sinh (k z)],
$$

where $c$ is the cohesion of the surrounding rock; $K$ is the coefficient of general solution; $z$ is any point along the anchor cable axis. 
Interfacial shear stress of surrounding rock mass is as follows:

$$
\tau(\mathrm{z})=\frac{k p}{2 \pi \mathrm{a}}[c \tanh (k l) \cosh (k z)-\sinh (k z)]
$$

The bearing capacity of the anchoring balanced arch bearing structure is as follows:

$$
q=\frac{Q(1+\sin \theta)(l-D)}{D^{2}(1-\sin \theta)(R+l-D)}
$$

where $q$ is the bearing capacity of the $\operatorname{arch}, \mathrm{kN} ; \mathrm{Q}$ is the anchor cable prestress, $\mathrm{kN}$; $D$ is the anchor cable spacing, $\mathrm{m} ; R$ is the half of the roadway span, $\mathrm{m} ; \theta$ is the internal friction angle of coal-rock mass, $\left({ }^{\circ}\right)$.

According to Eq. (6)-(8), increasing the prestress of the anchor cable (or increasing the support strength in a disguised way by increasing the support density) contributes to the stress diffusion of the anchor cable. It also helps to increase the damage resistance of the weak surface. There is a negative correlation between the anchorage balance arch and the row spacing between the anchors. Under the condition of weak roof lithology and obvious laminated characteristics, increasing the strength of anchor cable support is beneficial to the stability of the roadway surrounding rock.

Strata stratification is obvious within $5 \mathrm{~m}$ of the roof of 2201 return air roadway, and rebar bolt obviously cannot effectively control deep separation. The large row spacing between the anchor cable leads to the fact that a single anchor cable acts alone and cannot form an effective superimposed compression body in the same section (as shown in Figure 9). This eventually causes the roof to sag as a whole. Therefore, the anchor cable with row spacing of $2400 \times 2400 \mathrm{~mm}$ fails to form an arch-bearing structure. It also fails to maximize the use of the overall stiffness and self-bearing capacity of the surrounding rock within the support range.

4.2. Numerical Analysis of Anchor Cable Support. To effectively maintain the stability of the roof of 2201 return air roadway and reduce engineering rework, the parameters of the roof with composite layered soft rock characteristics were optimized. The original anchor cable support parameters were optimized from $2400 \times 2400 \mathrm{~mm}$ interrow spacing, 2-2 layout, to $1600 \times 1600 \mathrm{~mm}$ interrow spacing, 2-3-2 layout. The numerical simulation analysis was carried out for different support schemes [32]. The rebar bolt support resistance is $120 \mathrm{kN}$, and the anchor cable support resistance is $350 \mathrm{kN}$. Vertical stress nephogram in the mudstone interlayer at $2 \mathrm{~m}$ of the roof and between two rows of anchor cables in roadway were, respectively, intercepted, as shown in Figure 10.

Figure 9 shows that the superposition value of the stress field in the bolt support range is the largest under different support schemes. With the change of anchor cable supporting density, the stress gap within the anchor cable supporting range is very large. The stress at $2 \mathrm{~m}$ above the roof (in the

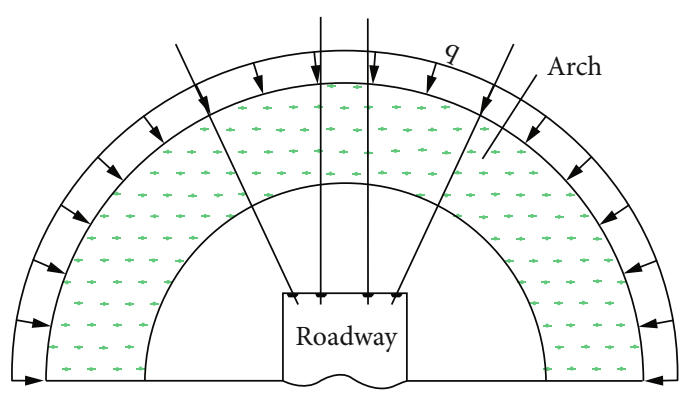

FIGURE 9: Anchorage equilibrium mechanical model.

mudstone interlayer) of the original support scheme does not diffuse effectively. The stress tends to be distributed at the point and was relatively scattered. The stress is concentrated around the anchor cable, and the maximum stress concentration is $0.1967 \mathrm{MPa}$, as shown in Figure 10(a). The maximum stress between the two rows of anchor cables in the original support is only $0.1987 \mathrm{MPa}$, as shown in Figure 10(b). In the reinforced support scheme, the stress is effectively diffused at $2 \mathrm{~m}$ above the roof, and the high stress under the action of the anchor cable is connected into sheets, with the maximum stress concentration of $0.3000 \mathrm{MPa}$. However, the stress in the middle of the roadway with the greatest roof caving hidden danger is small, as shown in Figure 10(c). The maximum stress between the two rows of anchor cables in the original support significantly increased to $0.8352 \mathrm{MPa}$, but the stress diffusion effect was poor, as shown in Figure 10(d). The stress of the optimized support scheme is smaller than that of the reinforcement scheme but larger than that of the original support scheme. In addition, the stress at $2 \mathrm{~m}$ above the roof is effectively diffused, and the high stress under the action of the anchor cable is connected into sheets. The maximum stress concentration is $0.2657 \mathrm{MPa}$, and the maximum stress concentration is in the middle of the roadway, as shown in Figure 10(e). In the optimized support scheme, the maximum stress between the two rows of anchor cables increased significantly to $0.2824 \mathrm{MPa}$, and the high stress zone was uniform, as shown in Figure 10(f).

The change of vertical stress caused by the change of anchor cable supporting density is not the same order of magnitude as the original rock stress $[19,30]$. However, for the surrounding rock already in the plastic zone, the stress action mode within the supporting range can be effectively improved by changing the supporting parameters and layout of the anchor cable $[21,33]$. The effective diffusion of support resistance within the support range can increase the thickness of the bearing ring, increase the bearing capacity, and promote the stability of the surrounding rock [34]. For the roof with a large potential instability range, a certain supporting density can avoid local roof leakage caused by too large row spacing between anchor cable $[29,35,36]$. In addition, compared with the original scheme, the number of anchor cable increased by $0.625 / \mathrm{m}$, but the number of anchor cable decreased by $1.042 / \mathrm{m}$ compared with the reinforcement scheme of the $800-1200 \mathrm{~m}$ section. It has certain economic advantages. 


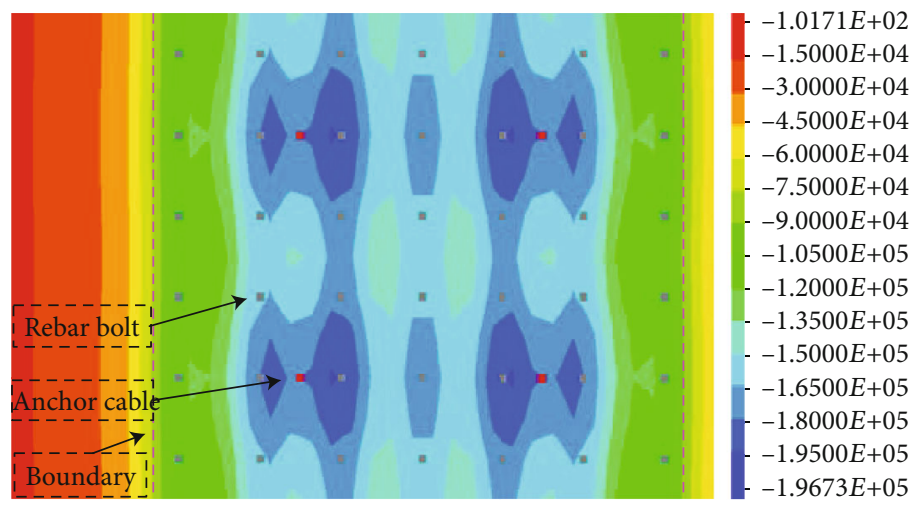

(a) Vertical stress at $2 \mathrm{~m}$ above the original supporting roof

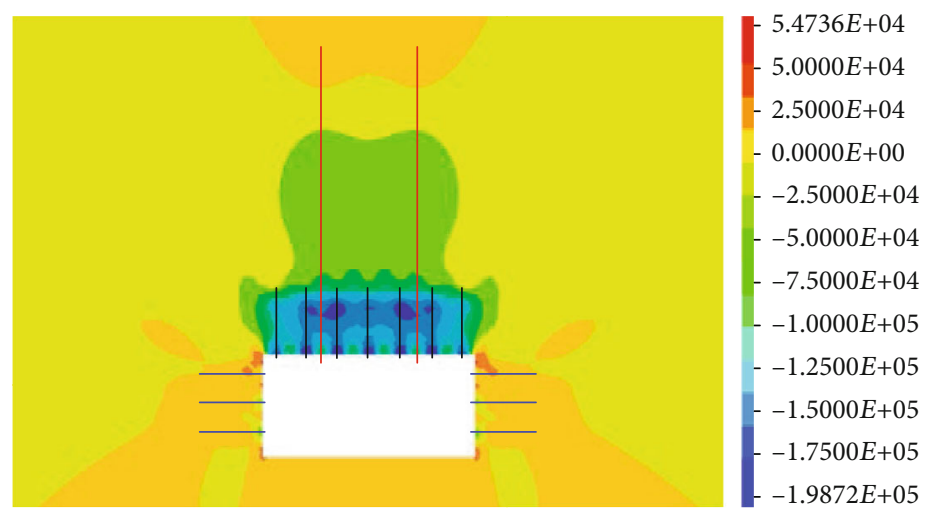

(b) Vertical stress of roadway profile under original support

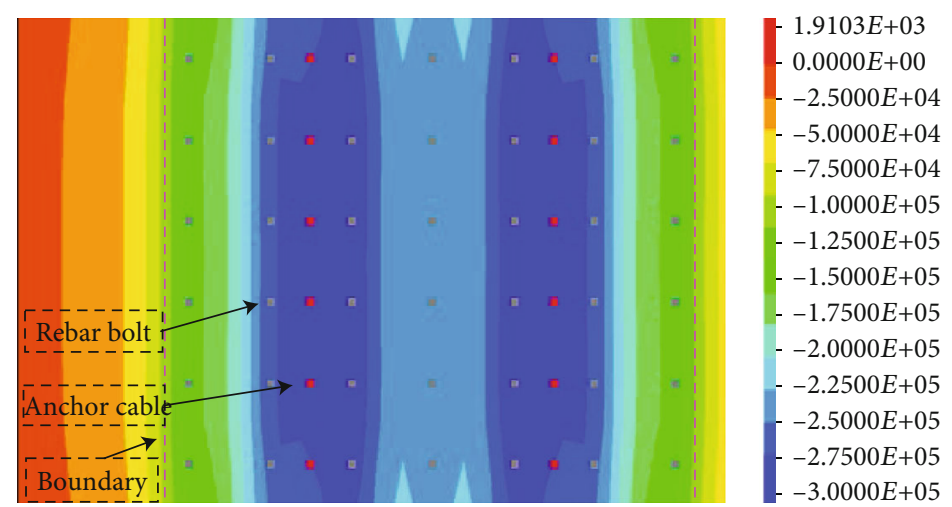

(c) Vertical stress at $2 \mathrm{~m}$ above reinforced supporting roof

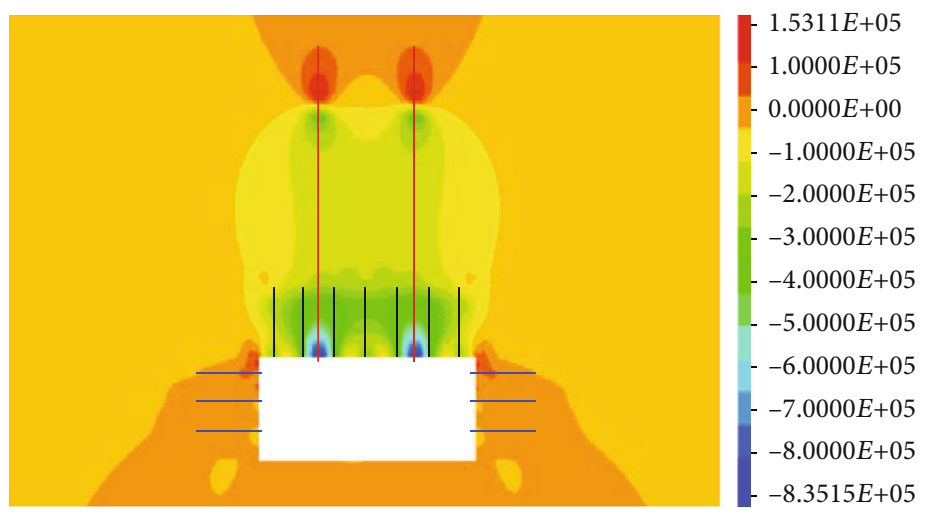

(d) Vertical stress of roadway profile under reinforced support

Figure 10: Continued. 


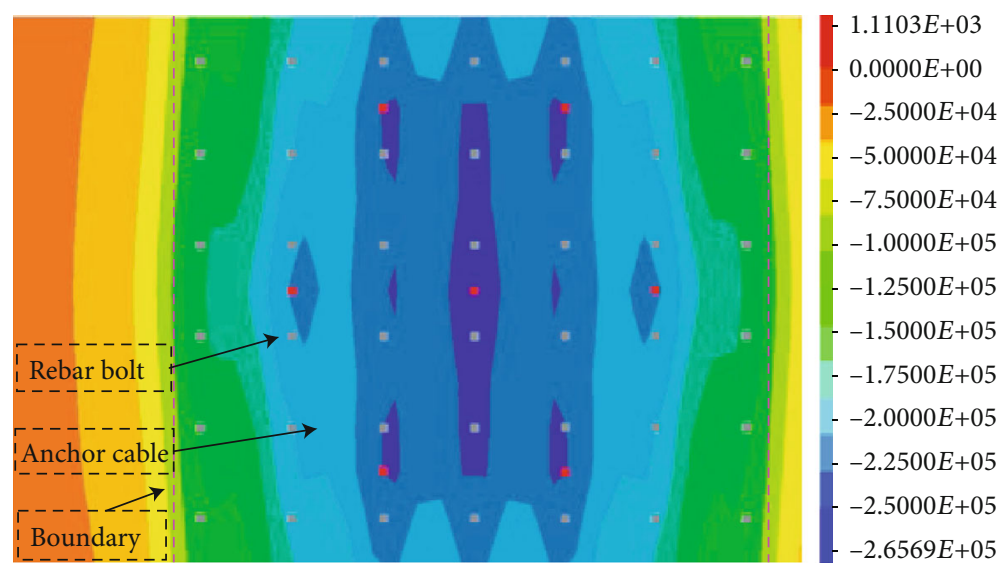

(e) Vertical stress at $2 \mathrm{~m}$ above the optimized supporting roof

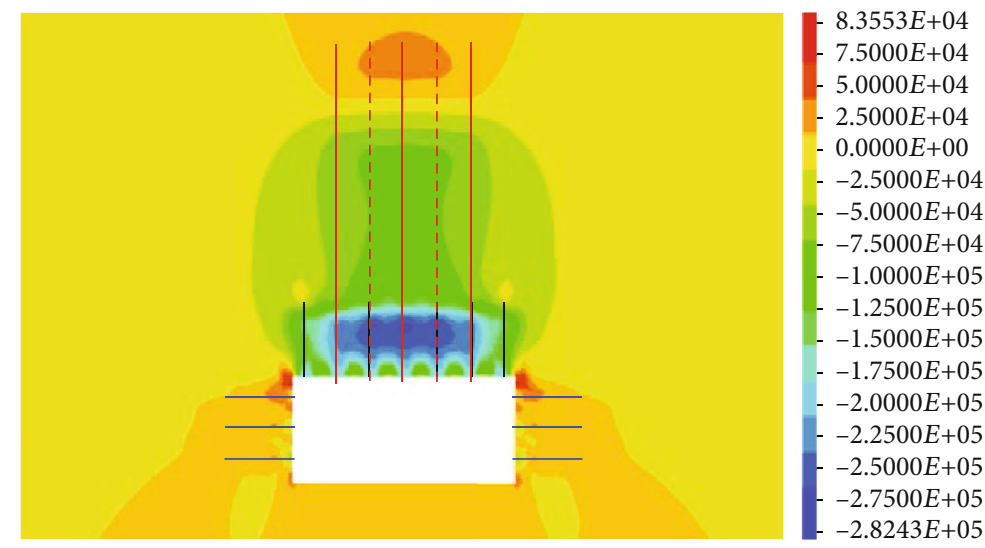

(f) Vertical stress of roadway profile under optimized support

FIGURE 10: Anchor cable support stress nephogram.

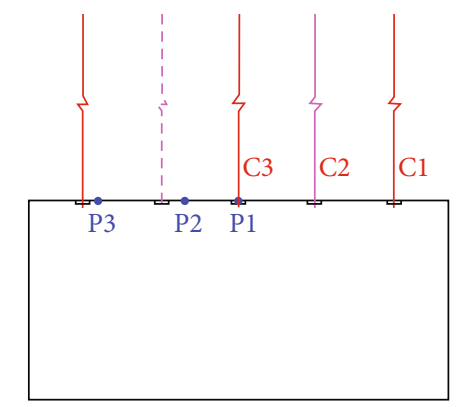

(a) Schematic diagram of section position

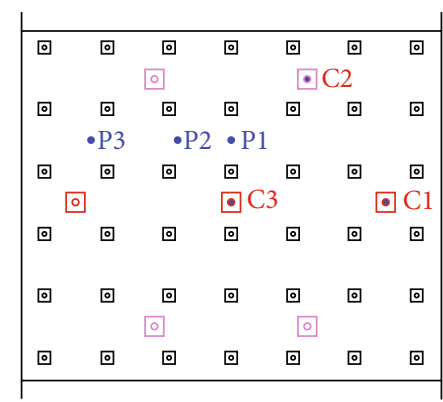

(b) Schematic diagram of plane position

FIGURE 11: Monitoring point layout schematic.

\section{Field Application of Optimized Support Parameters}

We have carried out the field application of the optimization scheme in 2201 return air roadway at $1200 \sim 1760 \mathrm{~m}$ in the Menkeqing Coal Mine. The optimization scheme is to optimize the original row spacing $2400 \times 2400 \mathrm{~mm}$ and 2-2 layout to $1600 \times 1600 \mathrm{~mm}$ and 2-3-2 layout. The plan of roof optimization scheme is shown in Figure 9(e).
We arranged one measuring point every $50 \mathrm{~m}$ within the range of $1210 \mathrm{~m} \sim 1710 \mathrm{~m}$, and a total of 11 measuring points were arranged. The roof stability of the roadway is better after the optimized support scheme is applied in the field. After the tunneling is stable, the maximum settlement of each measuring point in the roadway is between 56 and $82 \mathrm{~mm}$, and the stress of anchor cable is between 201 and $260 \mathrm{kN}$. Representative monitoring points are selected for data analysis. The layout of monitoring points at $1360 \mathrm{~m}$ is shown in 

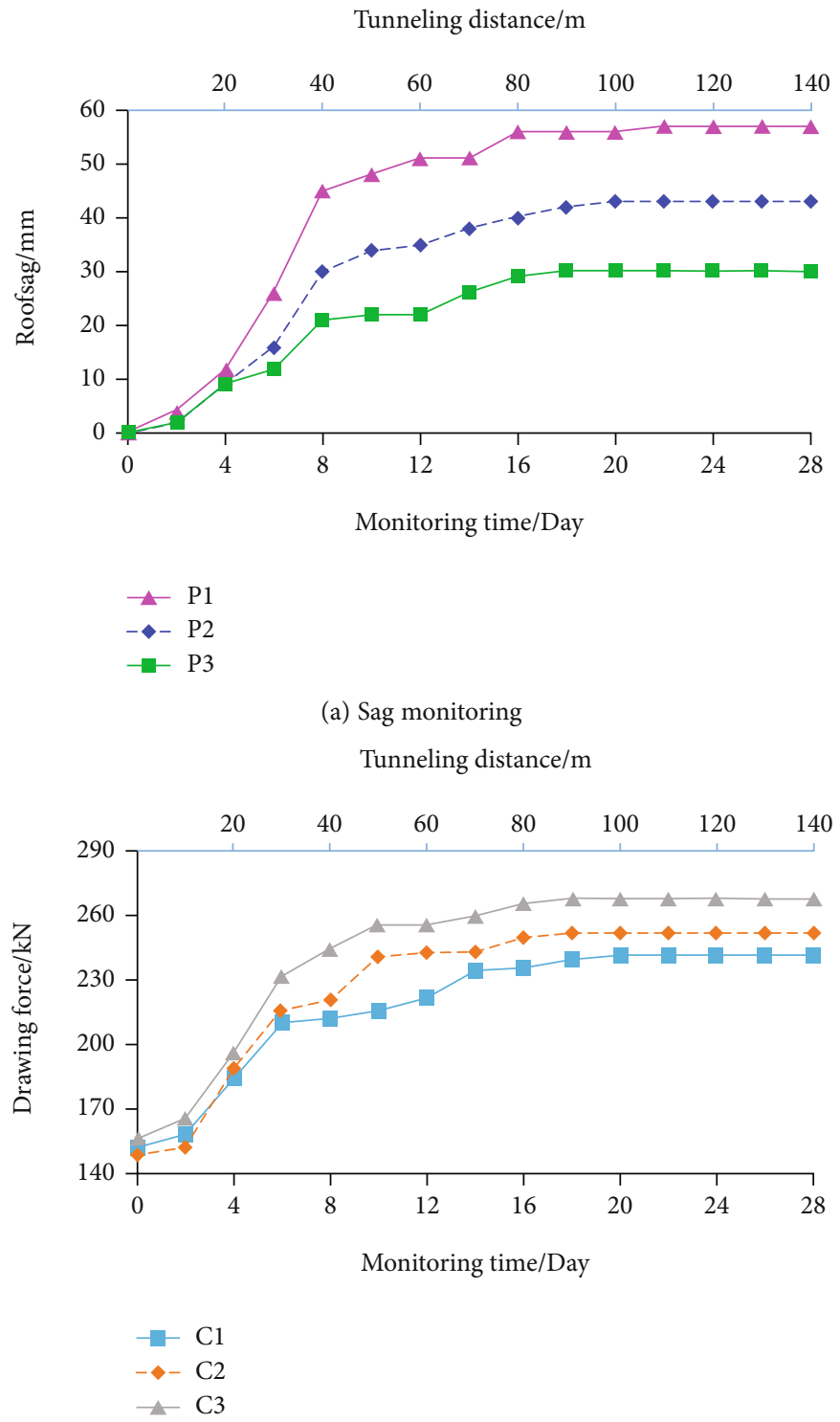

(b) Anchor cable stress monitoring

FIGURE 12: Monitoring data.

Figure 11, in which P1-P3 are sag monitoring points and C1$\mathrm{C} 3$ are anchor cable stress monitoring points.

Figure 12 shows the data measured at representative monitoring points. During tunneling, the maximum subsidence of the roadway at $1360 \mathrm{~m}$ is between 33 and $57 \mathrm{~mm}$, and the maximum subsidence of the roadway is at the central position ( $\mathrm{P} 1$ point), which is $57 \mathrm{~mm}$. The deformation rate of the roadway reached its maximum within 4-8 days after tunneling, and the monitoring point lagged behind the tunneling working face by about $40 \mathrm{~m}$. 20 days after tunneling, that is, the roadway gradually becomes stable after $100 \mathrm{~m}$ behind the working face. Similar to the deformation law of the roof, the stress of the anchor cable is the largest at the measuring point $(\mathrm{C} 3)$ in the center of the roadway, and the change is the largest in the 4th to 12 th day after roadway excavation. After 16 days, that is, after the monitoring point lagged behind the tunneling work by $80 \mathrm{~m}$, the stress of the anchor cable gradually stabilized.

\section{Conclusion}

Through the systematic study on the failure characteristics of the surrounding rock and the effect of anchor cable support in deep mining roadway, we mainly get the following conclusions.

(1) The main reason for the roof subsidence of the mining roadway is that the roof structure of the roadway is complex, and the layer structure is obvious. After softening by water, the strength difference between layers is great, and the bond between layers is poor, which aggravates the roof separation 
instability. The failure modes of different composite roofs are analyzed

(2) The surrounding rock of deep mining roadway is affected by the high stress environment, which leads to a large plastic zone. The roof interlayer structure causes the plastic zone of the roof to expand rapidly in the soft strata. The position, thickness, and strength of the interlayer have a great influence on the morphology and size of the plastic zone of surrounding rock

(3) Theoretical derivation proves that there is a negative correlation between the anchoring balance arch and the row spacing between the anchoring cables with the composite roof. The distribution of roof support resistance under different anchor cable supporting parameters is verified by numerical simulation. Reasonable arrangement of anchor cable is conducive to the full extension of supporting the resistance in the roof

(4) Under the condition of weak roof lithology and obvious composite layered characteristics, increasing the strength of anchor cable support is conducive to the stability of the roadway surrounding rock. Based on the research results, the supporting parameters of roadway anchor cable are optimized and applied in the field. No surrounding rock instability occurred after field application

\section{Data Availability}

The data used to support the findings of this study are available from the corresponding author upon request.

\section{Conflicts of Interest}

The authors declare no conflict of interest.

\section{Authors' Contributions}

C. Li and W.L. Zhang performed the conceptualization. C. Li and T.H. Huo performed the methodology. C. Li, R. Yu, and X.D. Zhao performed the investigation. C. Li and M. Luo performed the writing.

\section{Acknowledgments}

This work was partially supported by the National Natural Science Foundation of China (Grant no. 51804117).

\section{References}

[1] H. P. Kang, G. Xu, B. M. Wang et al., "Forty years development and prospects of underground coal mining and strata control technologies in China," Journal of Mining and Strata Control Engineering, vol. 1, no. 1, pp. 7-39, 2019.

[2] H. Y. Wang, X. Y. Fang, F. Du et al., "Three-dimensional distribution and oxidation degree analysis of coal gangue dump fire area: a case study," Science of The Total Environment, vol. 772, article 145606, 2021.

[3] M. G. Qian, P. W. Shi, and J. L. Xu, Mining Pressure and Strata Control, China University of Mining and Technology Press, 2010.

[4] C. Zhang, S. H. Tu, and Y. X. Zhao, "Compaction characteristics of the caving zone in a longwall goaf: a review," Environmental Earth Sciences, vol. 79, pp. 1-27, 2019.

[5] X. F. Guo, Z. Q. Zhao, X. Gao, X. Y. Wu, and N. J. Ma, “Analytical solutions for characteristic radii of circular roadway surrounding rock plastic zone and their application," International Journal of Mining Science and Technology, vol. 29, no. 2, pp. 263-272, 2019.

[6] Z. Q. Zhao, N. J. Ma, H. Liu, and X. F. Guo, “A butterfly failure theory of rock mass around roadway and its application prospect," Journal of China University of Mining \& Technology, vol. 47, no. 5, pp. 969-978, 2018.

[7] Y. Yu, L. Y. Zhang, J. F. Lu, B. C. Chen, X. Q. Zhao, and L. M. Liu, "Research on the evolution characteristics of floor stress and reasonable layout of roadways in deep coal mining," Geofluids, vol. 2021, 14 pages, 2021.

[8] B. Ghabraie, G. Ren, X. Zhang, and J. Smith, "Physical modelling of subsidence from sequential extraction of partially overlapping longwall panels and study of substrata movement characteristics," International Journal of Coal Geology, vol. 140, no. 15, pp. 71-83, 2015.

[9] P. K. Kaiser, S. Yazici, and S. Maloney, "Mining-induced stress change and consequences of stress path on excavation stability - a case study," International Journal of Rock Mechanics and Mining Sciences, vol. 38, no. 2, pp. 167-180, 2001.

[10] N. J. Ma, X. D. Zhao, Z. Q. Zhao, J. Li, and X. F. Guo, "Stability analysis and control technology of mine roadway roof in deep mining," Journal of China Coal Society, vol. 40, pp. 2287-2295, 2015.

[11] Y. Sun, G. Li, J. Zhang, and D. Qian, "Experimental and numerical investigation on a novel support system for controlling roadway deformation in underground coal mines," Energy Science \& Engineering, vol. 8, no. 2, pp. 490-500, 2020.

[12] C. Li, X. F. Guo, T. H. Huo, and R. Liu, "Coal pillar design of pre-excavated double equipment withdrawal channel and its surrounding rock stability control," Journal of Huazhong University of Science and Technology (Natural Science Edition), vol. 49, no. 4, pp. 1-7, 2021.

[13] F. Du, K. Wang, X. Zhang, C. Xin, L. Shu, and G. Wang, "Experimental study of coal-gas outburst: Insights from coal-rock structure, gas pressure and adsorptivity," Natural Resources Research, vol. 29, pp. 2481-2493, 2020.

[14] Y. Y. Li, K. Xie, Y. M. Sun, S. H. Li, and X. H. An, "Stress and deformation analysis and reinforcement time selection of composite foundations in shallow loess tunnels," Chinese Journal of Rock Mechanics and Engineering, vol. 38, no. 11, pp. 2332-2343, 2019.

[15] M. Rezaei, M. F. Hossaini, and A. Majdi, "Development of a time-dependent energy model to calculate the mininginduced stress over gates and pillars," Journal of Rock Mechanics and Geotechnical Engineering, vol. 7, no. 3, pp. 306-317, 2015.

[16] Q. C. Zhao and B. J. Fu, "Study on loose zone testing and support technology of roadway surrounding rock affected by dynamic pressure," Journal of Mining and Strata Control Engineering, vol. 2, pp. 49-56, 2020. 
[17] H. P. Kang, "Spatial scale analysis on coalmining and strata control technologies," Journal of Mining and Strata Control Engineering, vol. 2, no. 2, pp. 5-30, 2020.

[18] X. F. Guo, Z. Q. Zhao, X. Gao, Z. K. Ma, and N. J. Ma, “The criteria of underground rock structure failure and its implication on rockburst in roadway: a numerical method," Shock and Vibration, vol. 2019, 12 pages, 2019.

[19] J. Li, "The coal pillar design method for a deep mining roadway based on the shape of the plastic zone in surrounding rocks," Arabian Journal of Geosciences, vol. 13, no. 12, article 5501, 2020.

[20] G. Li, F. S. Ma, J. Guo, H. J. Zhao, and G. Liu, "Study on deformation failure mechanism and support technology of deep soft rock roadway," Engineering Geology, vol. 264, article 105262, 2020.

[21] G. R. Feng and P. F. Wang, "Simulation of recovery of upper remnant coal pillar while mining the ultra-close lower panel using longwall top coal caving," International Journal of Mining Science and Technology, vol. 30, no. 1, pp. 55-61, 2020.

[22] C. Jia and C. C. Hu, "Instability mechanism and control technology of longwall entries driving along the gob in a thick coal seam," Journal of Mining and Strata Control Engineering, vol. 2, no. 4, pp. 38-45, 2020.

[23] Z. Q. Zhao, N. J. Ma, X. F. Guo, X. D. Zhao, and L. Fan, "Falling principle and support design of butterfly-failure roof in large deformation mining laneways," Journal of China Coal Society, vol. 41, no. 12, pp. 2932-2939, 2016.

[24] F. Q. Gao, "Use of numerical modeling for analyzing rock mechanicproblems in underground coal mine practices," Journal of Mining and Strata Control Engineering, vol. 1, no. 1, pp. 21-28, 2019.

[25] H. Molladavoodi and M. Rahmati, "Dilation angle variations in plastic zone around tunnels in rocks-constant or variable dilation parameter," Journal of Central South University, vol. 25, no. 10, pp. 2550-2566, 2018.

[26] F. Du and K. Wang, "Unstable failure of gas-bearing coal-rock combination bodies: insights from physical experiments and numerical simulations," Process Safety and Environmental Protection, vol. 129, pp. 264-279, 2019.

[27] M. K. Jia, "Research on roof falling mechanism of deteriorative strata combination supported by bolts," Rock and Soil Mechanics, vol. 28, no. 7, pp. 1333-1337, 2007.

[28] T. Yu, G. M. Zhao, X. R. Meng, X. Cheng, and G. J. Li, “Stability analysis and supporting parameter design of composite roof," Coal Science and Technology, vol. 48, no. S1, pp. 1924,2020 .

[29] C. Li, W. L. Zhang, N. Wang, and C. Hao, "Roof stability control based on plastic zone evolution during mining," Journal of Mining \& Safety Engineering, vol. 36, no. 4, pp. 753-761, 2019.

[30] C. Yuan, L. Fan, J. F. Cui, and W. J. Wang, "Numerical simulation of the supporting effect of anchor rods on layered and nonlayered roof rocks," Advances in Civil Engineering, vol. 2020, 14 pages, 2020.

[31] J. K. Li and H. Wang, "Ground support of interbedded rock roof in a deep roadway with fully-anchored cables," Journal of Mining and Strata Control Engineering, vol. 2, no. 3, pp. 14-22, 2020.

[32] F. Pellet, M. Roosefid, and F. Deleruyelle, "On the 3D numerical modelling of the time-dependent development of the damage zone around underground galleries during and after excavation," Tunnelling and Underground Space Technology, vol. 24, no. 6, pp. 665-674, 2009.

[33] M. F. Cai, "Key theories and technologies for surrounding rock stability and ground control in deep mining," Journal of Mining and Strata Control Engineering, vol. 2, no. 3, pp. 5-13, 2020.

[34] H. P. Kang, "Analysis on load-bearing ring in surrounding rock of roadway," Rock and Soil Mechanics, vol. 17, no. 4, pp. 84-89, 1996.

[35] C. Li, Z. Wu, W. L. Zhang, Y. H. Sun, C. Zhu, and X. H. Zhang, "A case study on asymmetric deformation mechanism of the reserved roadway under mining influences and its control techniques," Geomechanics and Engineering, vol. 22, no. 5, pp. 449-460, 2020.

[36] C. X. Zhao, Y. M. Li, G. Liu, and X. Meng, "Mechanism analysis and control technology of surrounding rock failure in deep soft rock roadway," Engineering Failure Analysis, vol. 115, article 104611, 2020. 